\title{
TRADUÇÃO
}

\section{Mudança de significado do parlamentarismo ${ }^{1}$}

\section{Otto Kirchheimer}

Diz-se com frequência, sobre a Constituição de Weimar atualmente vigente, que ela teria criado a forma democrática de Estado na Alemanha e introduzido o sistema parlamentarista. Aqui, as expressões "parlamentarista" e "democrático" são, na maioria das vezes, usadas em conjunto ou uma ao lado da outra, de maneira que involuntariamente surge a impressão de que elas sempre teriam tido o mesmo significado no curso da história, de que uma não seria pensável sem a outra. Esse é um engano teórico de grande alcance que - se fosse de outra forma, a constatação não seria importante para nós - pode levar, e já levou, a erros desastrosos na práxis política.

Em sua configuração tradicional, o parlamentarismo é a forma clássica por meio da qual a burguesia dominava o Estado e a sociedade no século XIX. Restringindose meramente à observação das relações internas à Alemanha, por muito tempo se acreditou que as grandes oposições políticas desse século encontravam sua expressão na antítese "Estado da autoridade [Obrigkeitsstaat] e Estado popular", formulada pelo professor liberal Hugo Preuß. Com isso deixou-se de ver que aqui se tratava apenas de um último combate à retaguarda do absolutismo feudal, que - mais tarde na Alemanha, mais cedo em outros países - abriria caminho para o domínio da burguesia - primeiro na forma velada da transição da monarquia constitucional.

Três princípios políticos determinados, identificáveis e passíveis de formulação estavam na base do parlamentarismo, o sistema político de poder da burguesia no século XIX:

1. a crença de que exclusivamente as "camadas de posses e formação" - como o par clássico de palavras, tão elucidativo em sua composição, de Rudolf von Gneist, que, nos anos setenta e oitenta do século XIX, desempenhava o mesmo papel que hoje desempenha o professor Kahl do Partido Popular Alemão (Deutsche Volkspartei) - seriam vocacionadas para o exercício das funções

1 Kirchheimer, O. Bedeutungswandel des Parlamentarismus. Jungsozialistische Blätter, n. VII, caderno 10, outubro de 1928, republicado na coletânea organizada por Wolfgang Luthardt: Kirchheimer, O. (1981). Von der Weimarer Republik zum Faschismus: Die Auflösung der demokratischen Rechtsordnung. Frankfurt: Suhrkamp, pp.58-63 [Nota da tradutora (N. T.)]. Tradução de Bianca Tavolari. 
políticas e para a ocupação dos cargos públicos mais elevados;

2. a crença de que o que é útil e certo para a nação poderia ser encontrado na e por meio da discussão pública no parlamento;

3. a firme adesão ao princípio do Estado de direito.

Aquela proposição sobre a capacidade e a dignidade políticas exclusivas das camadas de posses e formação, que foi justificada por seus defensores de então por meio da referência aos impostos mais altos pagos pelas classes proprietárias, era a base teórica de todo direito de voto vinculado a uma determinada quantia de renda e propriedade (voto censitário). O voto censitário foi o meio técnico da burguesia no século XIX (que ainda não dispunha de um monopólio da imprensa tão irrestrito e efetivo, tal como seus netos no século XIX) de manter as grandes massas afastadas do exercício de influência sobre seus destinos políticos e para assegurar, assim, que o domínio do Estado permanecesse exclusivamente em suas mãos. 0 princípio basilar da burguesia no século XIX, o princípio do Estado de direito, é dificilmente compreensível para nós mesmo que até nos círculos do partido se fale da ideia sagrada do Estado de direito; aqui, entretanto, nunca se nota que, sob a perspectiva da história das ideias, o significado do Estado de direito era completamente outro no século XIX se comparado à sua função na vida política do século XX. Naquela época, a exigência do Estado de direito tinha um sentido duplo: em primeiro lugar, esse conceito serviria para que a burguesia alcançasse e assegurasse a vitória definitiva sobre os resíduos absolutistas do sistema monarquista, para garantir que o arbítrio de cada órgão individual de governo e da administração fosse restringido ao máximo possível na medida em que se criava uma série de normas legislativas precisas. Além disso, as necessidades do comércio e da troca exigiram uma segurança jurídica que fosse a maior possível; cada vendedor e cada industrial deveriam conseguir saber, antecipadamente, o quão bem sucedidos eles seriam quando se dirigissem aos órgãos estatais para implementar uma demanda - e eles tinham várias. O que temos em mente aqui se torna claro em uma imagem grotesca utilizada por Max Weber, o maior e mais perspicaz entre os eruditos burgueses alemães: a justiça seria uma máquina em que em cima se coloca o caso concreto e as custas judiciais para que, então, a solução fosse despejada na parte de baixo.

Já naquela época, tanto os representantes da burguesia quanto os porta-vozes literários do proletariado reconheciam o papel do sistema parlamentar, a diferença entre domínio parlamentar e democracia. O seguinte argumento perpassa todos os escritos políticos de Marx e Engels, do Manifesto Comunista, passando por As lutas de classes na França até $A$ guerra civil na França e o escrito de maturidade de Engels 
Internationales aus dem Volksstaat: “O poder estatal (Staatsgewalt) moderno é apenas um comitê que administra os negócios comuns de toda a burguesia" (Manifesto Comunista). "Democracia” era entendida como o domínio do povo como um todo, do povo trabalhador, em oposição ao domínio de um parlamento que surgiu por meio do voto censitário. E mesmo a burguesia reconheceu, em seus representantes mais distintos, que seu sistema parlamentar de então estava em completa oposição a um domínio democrático do povo. Em resumo: naquela época democracia significava a pressão geralmente não muito clara, mas sempre presente, das amplas massas em relação ao domínio político; o parlamentarismo era a corporificação do domínio da burguesia.

$\mathrm{O}$ que aconteceu com aqueles três principais pontos de apoio do sistema parlamentar do século XIX? Pesquisar sobre isso, sem sermos influenciados pelas opiniões sobre o valor e o desvalor do parlamentarismo que já eram dominantes na época, é agora nosso dever.

Por meio da revolução de 1918, caíram os últimos restos de um direito de voto baseado na classe. No Reich, o direito ao voto universal e igualitário já havia sido alcançado por meio da Constituição de Bismarck. O tão almejado princípio do voto proporcional também se realizou. A responsabilidade parlamentar dos ministros, sua completa dependência dos representantes do povo, tornou-se princípio constitucional. Muitos viram nisso a supressão definitiva do antigo sistema. Para nós, entretanto, não parece que esta conquista deva ser altamente estimada, uma vez que, já na monarquia constitucional, as camadas da burguesia que são decisivas até hoje exerciam uma influência - que, apesar de não ser estabelecida pelo direito estatal, não era menor em razão disso - sobre a formação da vontade das mais altas autoridades de governo. Frequentemente se afirma que, depois da queda do direito ao voto baseado em três classes (Drei-Klassen-Wahlrecht), depois da introdução de um voto proporcional universal, aquelas oposições entre a burguesia politicamente privilegiada e o operariado com menos direitos, tal como elas caracterizavam o século XIX, estariam superadas e que, hoje, na Alemanha, teríamos apenas cidadãos com direitos iguais; em síntese, teríamos um sistema que uniria, em si mesmo, democracia e parlamentarismo.

O que apontamos como o primeiro princípio do Estado burguês-parlamentar acabou por de fato cair. 0 voto censitário era o meio mais ingênuo de manter grandes camadas de eleitores afastadas. Mas seria um ponto de vista demasiadamente superficial se nos contentássemos com a constatação de que desapareceu um meio de afastar as camadas proletárias da representação enérgica de seu interesse de classe, sem nos preocuparmos em perguntar se o objetivo almejado não é hoje alcançado por outros meios. No século XX, a burguesia aprendeu a se servir de um poder muito efetivo, que ela não conhecia anteriormente nessa extensão e do qual 
não tinha sentido necessidade de se servir de maneira organizacional antes. Com ajuda do dinheiro, ela criou um grande número de instituições por meio das quais ela falsifica a formação da vontade estatal. Seu meio mais importante é sua imprensa. Para mostrar a vantagem descomunal que a burguesia consegue em razão do capital que está à sua disposição, basta apontar para um exemplo familiar a todos nós. Existe hoje uma organização influente chamada Partido Democrático (Demokratische Partei) - em razão de sua ideologia, ela é muito mais perigosa para o operariado do que seus inimigos públicos; mas infelizmente ainda não ficou suficientemente claro para os círculos dirigentes do partido que, por um lado, o capital financeiro e, por outro, industriais e agrários, por mais que possam não concordar em muitos pontos, têm exatamente a mesma opinião no ponto decisivo, o da manutenção da propriedade privada e da liberdade de contrato. Essa organização política, o Partido Democrático, deve sua existência somente às três empresas jornalísticas: Ullstein, Mosse e Frankfurter Sozietätsdruckerei. Por meio de sua posição de poder financeiro, a burguesia assumiu uma posição de poder velada no lugar de uma posição aberta. Ela concedeu o direito de voto igual e universal para, ao mesmo tempo, despojá-lo de seus mais importantes efeitos por meio da sua posição de poder financeiro.

O segundo princípio da burguesia parlamentarista, a crença na discussão pública no parlamento, que produz o resultado correto e racional para o bem do povo, pressupunha uma dada unidade política, tal como a burguesia do século XIX apresentava. Quando o proletariado chegou ao parlamento, esse princípio havia perdido o sentido. Na discussão pública, o representante do proletariado só podia dizer, ao representante da burguesia, que seu interesse exigia uma regulação específica, enquanto o representante dos burgueses partia daquilo que tornava seu interesse necessário, embora até hoje os parlamentares burgueses mostrem a particularidade de proclamar que seu interesse seria idêntico ao interesse da nação como um todo. Assim, um parlamento não é mais o lugar da discussão criativa, ele se tornou o local das declarações públicas de interesses de classe opostos, enquanto as verdadeiras decisões sobre questões políticas são tomadas em reuniões privadas e em comitês e encontros secretos. A ideia de uma decisão racional que deve ser obtida no parlamento entendido como o refúgio do progresso teve de dar lugar ao fato de que os interesses de classe são questões de poder para as quais não há outra racionalidade que não a necessidade de alcançar, para cada classe, o máximo do que the é possível sem ultrapassar o risco de sua correlação de poder. Nesse contexto pode ser apontado que maioria no parlamento e poder político real podem, mas não precisam coincidir. Maioria e poder são duas coisas distintas e a maioria no parlamento é apenas uma possibilidade - não absolutamente confiável - de conhecer a verdadeira correlação de poder.

A burguesia procurou se aproveitar da ideia do Estado de direito em relação 
ao proletariado de tal maneira a apontar que as leis seriam iguais para todos, que teriam validade igual e que, por isso, o proletariado não poderia exigir um tratamento especial. Contra este argumento basta fazer referência às palavras acertadas de Anatole France: “Em sua justiça majestática, a lei permite que pobres e ricos possam dormir debaixo de pontes". Na verdade, a ideia de Estado de direito ganhou hoje um sentido completamente diferente. Ela não é mais uma posição que pertence exclusivamente à burguesia, nem uma posição de ataque, como em seu período inicial, nem uma posição de defesa, como em seu período tardio. Hoje, a ideia de Estado de direito está situada entre proletariado e burguesia. Ela se tornou a linha divisória de dois grupos em luta, da qual ambos estão bastante distantes para sentir que ela seria a lei definitiva para a distribuição de poder. Isso deve ser ilustrado por meio de um exemplo. Hoje, nem empregadores nem empregados querem colocar tudo em jogo por meio de uma desavença individual; isso porque, hoje, cada uma de suas desavenças ultrapassa a luta de dois indivíduos isolados; por trás de cada um deles está seu grupo social, preparado para vir em ajuda a seu partido em cada caso importante; por isso o Estado estabeleceu todo um sistema jurídico que serve para resolver essas lutas sociais por meio de um caminho jurídico, para retirá-las da esfera dos participantes diretos, para neutralizar questões sociais de poder na forma de problemas de aplicação do direito. Então o sistema jurídico estatal tem hoje a função de criar um estado de equilíbrio nas relações entre burguesia e proletariado. O Estado de direito é, talvez, uma das formas externamente mais características para o valor de transição de nosso sistema político atual, para seu caráter provisório, para uma situação em que uma das classes já não é mais forte o suficiente, a outra ainda não é forte o suficiente para manter a exclusividade de seu sistema político. 